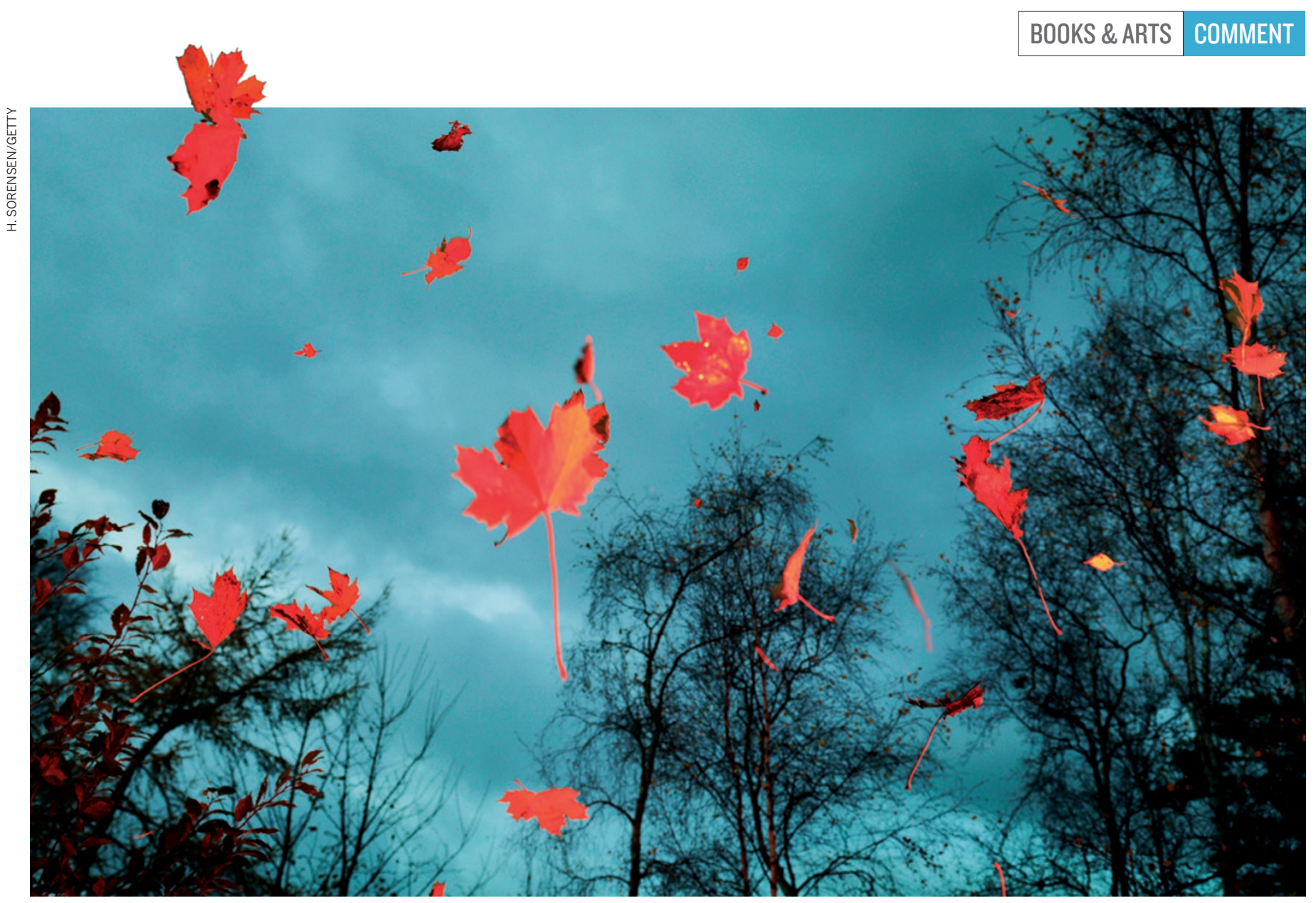

Leaves meet tough physical challenges such as wind and rain with an array of extraordinary coping mechanisms.

\title{
BIOPHYSICS
}

\section{Tales from the canopy}

\section{Sandra Knapp considers how the laws of physics influence the function} of leaves in myriad ways.

$\mathrm{W}$

e live highly networked lives at what often seems like warp speed. When you think about how complicated all that commuting, preparing and organizing is, spare a thought for the leaves above. As plant physiologist Steven Vogel reveals in The Life of a Leaf, coping with physical variables that humans barely notice - wind, rain, sunshine makes for a tough existence at leaf level.

Vogel celebrates serendipitous discoveries and ideas, describing his own in detail, and shows the general reader just how exciting science can be. His observations of rhododendron leaves rolling into cigar-shaped tubes led him to experiments showing how leaves keep themselves warm. And his use of down time in a local wind tunnel one Thanksgiving inspired him to discover how leaves handle high winds. Both are great examples of how a seemingly crazy idea can ultimately generate new understanding.
Leaves cover vast stretches of terrestrial Earth's surface, and enable much of life itself through oxygen-producing photosynthesis. Yet we only really notice this multilayered canopy when leaves change colour in the autumn, drop off owing to drought or block the sunlight we crave. The

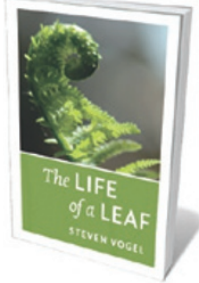

The Life of a Leaf STEVEN VOGEL Univ. Chicago Press: 2012. 320 pp. $\$ 35$, $£ 22.50$ physical environment that leaves experience is like our own, but subtly different, because leaves can't move much. Vogel lucidly outlines the physics and engineering challenges that this presents.

His central focus is on a leaf's function, not its structure. He explores the amazing things that physical features do for organisms: how daffodils bloom through the snow without ice crystals bursting their cells; how sap rises to the tops of the tallest trees; how leaves avoid tearing in strong winds. The physics of these phenomena is incredible.

We usually think of physics as informing biology. Vogel shows that in many cases, it is the other way round. Physiologists have discovered basic principles in biological systems that have later been shown to be universal and have become the stuff of fluid dynamics. For example, nineteenth-century French physiologist Jean Louis Marie Poiseuille devised an equation explaining the pressure gradient for liquid upflow in small tubes, such as the conducting tissue of plants. And German physiologist Adolf Eugen Fick formulated the law that describes the central relationship of diffusion across gradients.

Vogel weaves equations and jokes together seamlessly. For the many people who can't 'read' equations, he explains 
them verbally, then discusses them in a more conventional way in footnotes. He further enlivens the proceedings by linking the equations with the personalities and lives of the scientists after whom they are named. For instance, the Scholander bomb, a device used to measure pressure in stems, gets its name from the Scandinavian-born physiologist Per Scholander (1905-80), who was renowned for his ingenious experimental-apparatus designs. Vogel's approach certainly worked for me.

As for the jocularity, there is much that is quotable. I love the description of the superhydrophobicity of leaves as "particle pickup predilection", and the idea that ice is "toxic water" from a leaf's perspective. But some of the puns jar - the phrase "to a plant, our water loss problem would be a wet dream" struck me as condescending and crass.

Gags notwithstanding, Vogel does makes the conscientious reader work, although this is more of a challenge than a chore. His focus leaves some issues hanging - forcing us to dig further elsewhere. And he rightly notes that there is still a lot to discover. How, for example, do deciduous trees re-establish unbroken water columns through their trunks to the new leaves in spring?

He even urges readers to do their own demonstrations and experiments at home, to illustrate basic principles in a way that words never can. A loop of thread placed in a glass of water will not form a regular shape, but add a bit of detergent to reduce the surface tension and hey presto: a perfect circle (and party trick). And it is fun to whirl around in the garden holding a stick with leaves attached to the end - especially if you're demonstrating how the leaves behave in the 'wind' you create, which can easily reach 30 kilometres an hour.

The role of phylogeny - the evolutionary relationships between plants is completely left out of this book. Vogel is a proponent of the adaptationist programme, in which every feature has a function that serves the organism well. He pays lip service to an alternative view by referencing his late friend Stephen Jay Gould, but I think the role of chance in evolution deserves more than just a mention. Features of organisms do not always have a purpose. Sometimes they just are.

Probably the central theme of The Life of a Leaf is extracting the extraordinary from the ordinary. In a way, Vogel's view is that science is at its heart simple - and great fun. I couldn't agree more.

Sandra Knapp is a botanist at the Natural History Museum in London. e-mail:s.knapp@nhm.ac.uk

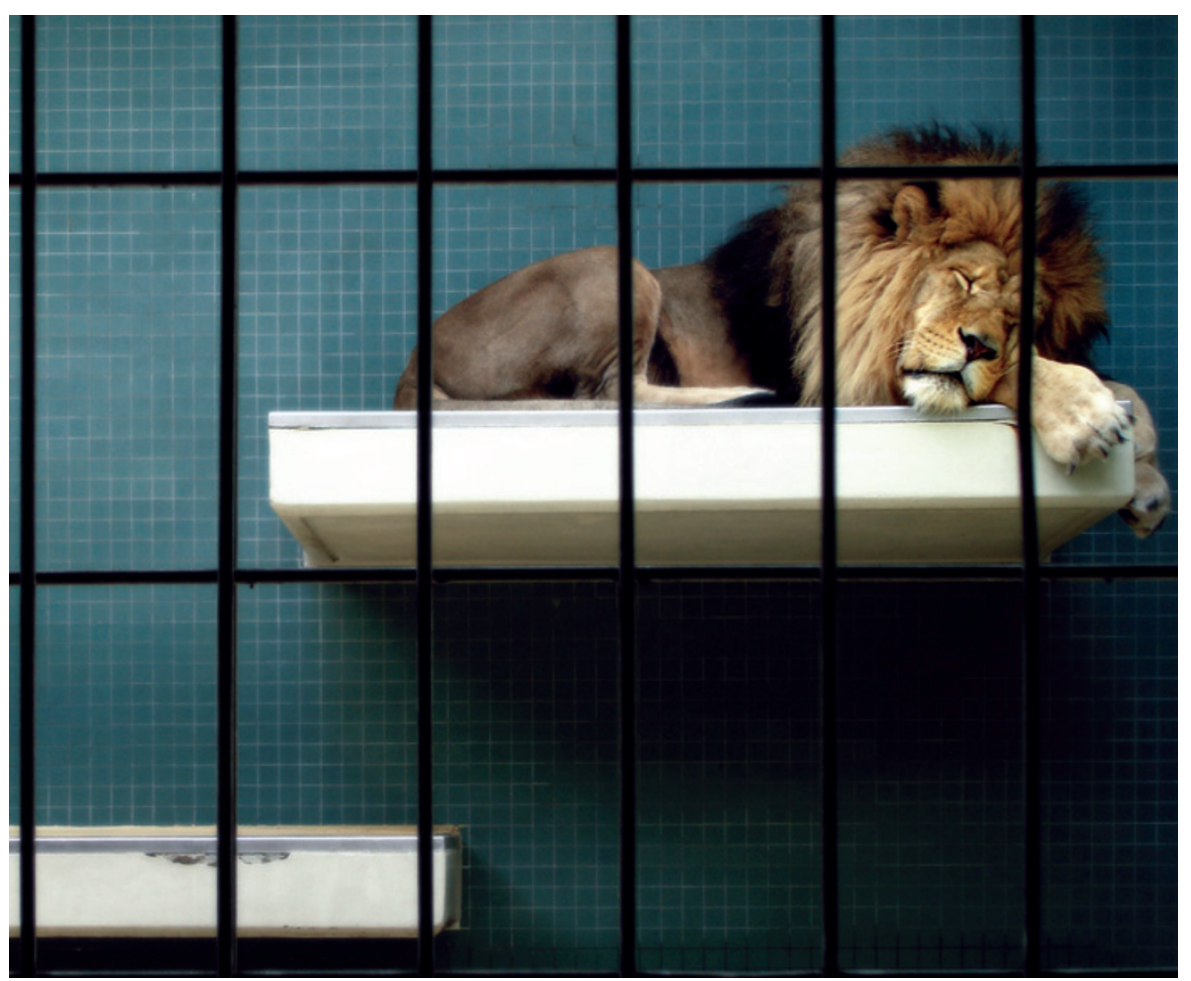

Life in a cage disconnects animals from the natural world and breeds apathy.

\section{ZOOLOGY}

\section{The animal inside}

\section{Josie Glausiusz contemplates a documentary on the human relationship with animals confined and stuffed.}

A lion lies asleep atop a glass roof inside a wire enclosure. Beneath the glass, within an enclosed walkway, tourists lift their smartphones and snap photos of the torpid feline. What do they see when they look at it - a magnificent beast, or a cowed one, disconnected from its natural world?

Questions about what we really see when we look at animals run throughout Bestiaire, a strange and unsettling documentary directed by Canadian Denis Côté. Awarded a Special Jury Prize at the 2012 Environmental Film Festival at Yale, held in New Haven, Connecticut, Bestiaire continually confounds the viewer, undermining our understanding of what it means to be wild, as it reflects our own confined lives.

The film unfolds over four seasons, shot mostly inside Parc Safari, a zoo in Hemmingford in Quebec, Canada. There is no narration and little dialogue, and disparate scenes seem to pop up at random. We move from art students sketching what looks like a stuffed baby deer to snow-filled pens in which woolly bison, llamas and horses lumber back and forth. Zebras stomp frantically. A melancholy monkey cuddles a stuffed teddy bear. In summer, geese waddle through tall grass and children take elephant rides and pat young deer.

People feature too. Guards watch and feed the animals through the mesh of the cages - and are themselves observed on closedcircuit cameras. At one point the film's focus shifts to a taxidermy studio in a Montreal basement, crammed with skulls and stuffed

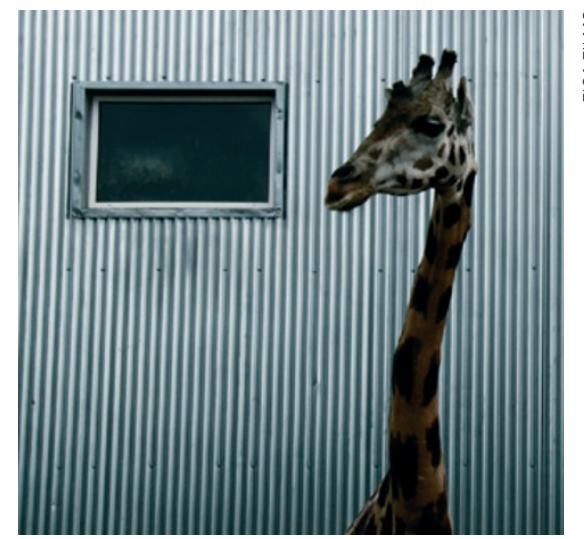

Bestiare raises unsettling questions about humanity's habit of gawking at confined animals. 